\title{
Paracetamol infusion-related severe hypotension and cardiac arrest in a child
}

\author{
Ayhan Yaman¹, Baver Demir², Fatma Burcu Belen³, Bülent Filik², Necibe Güneş², Faruk \\ Barlık $^{2}$, Tanıl Kendirli ${ }^{4}$ \\ ${ }^{1}$ Pediatric Intensive Care Unit, ${ }^{3}$ Division of Pediatric Hematology, ${ }^{2}$ Department of Pediatrics, Gaziantep Children's Hospital, \\ Gaziantep, ${ }^{4}$ Pediatric Intensive Care Unit,Department of Pediatrics, Ankara University Faculty of Medicine, Ankara, \\ Turkey.E-mail: dryamanayhan@yahoo.com.tr \\ Received: 16th February 2016, Revised: 30th March 2016, Accepted: 18th April 2016
}

SUMMARY: Yaman A, Demir B, Belen FB, Filik B, Güneş N, Barlık F, Kendirli T. Paracetamol infusion-related severe hypotension and cardiac arrest in a child. Turk J Pediatr 2016; 58: 550-553.

Paracetamol (also known as Acetaminophen) is an antipyretic, non-opioid analgesic, and non-steroidal anti-inflammatory drug (NSAID), and is one of the most commonly used medications worldwide. In recent years, IV paracetamol has been frequently used in hospitalized patients to reduce fever and pain. Significant adverse reactions associated with intravenous paracetamol are extremely rare. Typically reported adverse events include hypotension, malaise, hypersensitivity reaction, liver enzyme elevation, and thrombocytopenia. We present herein a case of IV paracetamol infusion-related severe hypotension and cardiac arrest.

Key words: Paracetamol, hypotension, cardiac arrest, child.

Paracetamol (also known as Acetaminophen) is an antipyretic, non-opioid analgesic, and non-steroidal antinrai-inflammatory drug (NSAID), and is one of the most commonly used medications worldwide. Intravenous (IV) paracetamol was first introduced in the hospital setting in $1985^{1,2}$. Significant adverse reactions associated with intravenous paracetamol are extremely rare, occurring at an approximate incidence of fewer than $1 / 10,000$. Typically reported adverse events include hypotension, malaise, hypersensitivity reaction, liver enzyme elevation, and thrombocytopenia ${ }^{3}$.

We present herein a case of paracetamol infusion-related severe hypotension and cardiac arrest. To our knowledge, there have been no previous cases of any child with paracetamol associated cardiac arrest.

\section{Case Report}

A 2-year 3 month-old girl patient applied to our emergency department because of persistent fever that had started three days previously. After medical examination, she was admitted to the hematology service due to febrile neutropenia. The patient's oral intake was not good, so intravenous paracetamol infusion was given to the patient to reduce her fever. As the patient was receiving 10mg/ $\mathrm{kg}$ paracetamol infusion, her general situation deteriorated (in the $5^{\text {th }}$ minute of infusion). The paracetamol infusion was stopped. The patient's blood pressure could not be measured and syncope occurred. Subsequently, cyanosis occurred in the patient followed by cardiac arrest. Cardiopulmonary resuscitation (CPR) was immediately applied to the patient. In the $15^{\text {th }}$ minute of CPR, the patient's circulatory system spontaneously reactivated. The patient was intubated. The patient was admitted to our pediatric intensive care unit. She was supported with mechanical ventilators in SIMV mode.

Laboratory tests showed the following results: white blood cell count, $1680 / \mathrm{mm}^{3}$; hemoglobin, $9.1 \mathrm{~g} / \mathrm{dl}$; platelet count, $292,000 / \mathrm{mm}^{3}$; glucose, $315 \mathrm{mg} / \mathrm{dl}$; blood urea nitrogen, $8 \mathrm{mg} / \mathrm{dl}$; creatinine, $0.55 \mathrm{mmol} / \mathrm{L}$; uric acid, $3.9 \mathrm{mg} / \mathrm{dl}$; total bilirubin, $0.23 \mathrm{mg} / \mathrm{dl}$; albumin, $3.2 \mathrm{~g} / \mathrm{dl}$; sodium, $134 \mathrm{mmol} / \mathrm{L}$; potassium, $4.5 \mathrm{mmol} / \mathrm{L}$; calcium, $7.8 \mathrm{mg} / \mathrm{dl}$; aspartate aminotransferase, $48 \mathrm{U} / \mathrm{L}$; alanine aminotransferase, $13 \mathrm{U} / \mathrm{L}$; prothrombin time (PT), 13.7 seconds; activated 
partial thromboplastin time (aPTT), 26.6 seconds; international normalized ratio, 1.05; C-reactive protein, $4.1 \mathrm{mg} / \mathrm{dl}$; and troponin I, $1.22 \mathrm{ng} / \mathrm{ml}$. Electrocardiography and echocardiography of the patient was normal.

The patient's postarrest medical treatment was adjusted. After the arrest, dopamine infusion at a rate of $10 \mu \mathrm{g} / \mathrm{kg} / \mathrm{min}$ was given to the patient. Convulsions that occurred when the patient was admitted to the intensive care unit repeated. Midazolam iv infusion of $0.2 \mathrm{mg} / \mathrm{kg} / \mathrm{h}$ was given to the patient. This was increased up to $0.4 \mathrm{mg} / \mathrm{kg} / \mathrm{h}$. The patient's brain tomography was evaluated as normal, but during the acute stage, due to the fact that ischemia and cerebral edema, could not be excluded hypertonic saline $(3 \% \mathrm{NaCl})$ at a dose of $10 \mathrm{ml} / \mathrm{kg}$ was loaded in 1 hour as a brain sparing treatment. Afterwards, $0.3 \mathrm{ml} / \mathrm{kg} / \mathrm{h}$ continuous hypertonic saline infusion was given.

Antihistamine and steroid treatment were given to the patient for anaphylactic shock. Following this, adrenaline infusion at a dose of $0.3 \mu \mathrm{g} /$ $\mathrm{kg} / \mathrm{min}$ was given to the hypotensive patient. A 5 Fr central venous catheter was inserted into the internal jugular vein of the patient for the reason that she was receiving multiple inotrope support. The patient was consulted with the pediatric allergy unit. Anaphylaxis or anaphylactic shock was not considered, because when the patient's situation worsened, respiratory distress or eruption did not occur. The patient started enteral feeding on the 2nd day of hospitalization in the pediatric intensive care unit and was extubated on the 4th day of hospitalization. The patient's brain magnetic resonance was evaluated as normal. On the $11^{\text {th }}$ day of hospitalization, she was discharged from the hospital with a good general condition, conscious and without any neurologic deficit. One month later, in her physical control checkup, the patient had no neurological deficit and her system check-up was completely normal.

\section{Discussion}

Paracetamol is one of the most commonly used drugs worldwide. Paracetamol has analgesic and antipyretic effects, but unlike the NSAIDs, it does not have peripheral anti-inflammatory effects ${ }^{4}$.Intravenous paracetamol is known to be safe and well tolerated. One of the first studies specifically examining the hemodynamic effects of the new ready-to-use formulation of IV paracetamol was published in $2010^{5}$. This study showed a significant decrease in systolic blood pressure (SBP) with the use of IV paracetamol.Boyleet $\mathrm{al}^{6}$., however, provided evidence that IV paracetamol can cause reduced blood pressure up to 60 minutes after infusion. Recently, Needleman ${ }^{7}$ investigated the safety of rapid infusion of IV paracetamol. In a retrospective chart review, IV paracetamol was found to cause statistically significant decreases in SBP, diastolic blood pressure (DBP) and mean arterial pressure (MAP). Our patient had severe hypotension and cardiac arrest due to paracetamol infusion. The patient's hypotension may have developed due to the rapidly administered paracetamol.

The currently used preparation of IV paracetamol is ready-to-use and available in solution due to the addition of stabilizing compounds. The IV paracetamol solution that was applied to our patient contained mannitol as inactive ingredient. Mannitol is secreted into the lumen of the nephron and causes a fluid shift resulting in increased urine production secondary to natriuresis. Due to osmotic forces, water is drawn from the peritubular blood and into the lumen of the nephron producing an increased volume of urine ${ }^{1}$. Consequently, a reduction in blood volume may be expected to occur with the increased production of urine. Previously, mannitol was found to cause a redirection of systemic blood volume to the kidneys, which most likely exacerbates the subsequent decreased blood volume associated with its use ${ }^{8}$. Hypovolemiais a common cause of hypotension. The diuretic nature of mannitol, even in small doses, has been reported to cause episodes of transient hypotension ${ }^{9}$. For the sake of consistency, studies that failed to observe hemodynamic changes but used (mannitolfree) IV propacetamol as a substitute for IV paracetamol should be considered separately in any analyses of the hemodynamic effects of IV paracetamol. The hypotension of the patient may be related to hypovolemia associated mannitol.

Intravenous paracetamol-induced hypotension maybe clinically important, especially in the setting of critical illness where it is most frequently reported ${ }^{5-7,10-14}$. Boyle et $a l^{6}$. suggested there might be a relationship between 
reduced skin blood flow and hypotension following administration of paracetamol in febrile patients. It has been reported in the literature that cardiac arrest occured in a adult patient after paracetamol infusion due to the prolongation of the QTC and hypokalemia ${ }^{15}$. There was no electrolyte abnormality in the patient's during her admission to pediatric intensive care unit. Electrocardiography of the patient was normal. Our patient is the first patient reported in the literature that had paracetamol associated cardiac arrest in children.

Cardiopulmonary arrest (CPA) in childhood is a tragic event, often resulting in death or poor neurologic outcome ${ }^{16}$. Clinical factors that influence survival include the environment in which the arrest occurs, the comorbidities of the child, the duration of "no flow" (period of time when there is no pulsatile flow, and the patient is not undergoing cardiopulmonary resuscitation) before resuscitation, the initial rhythm detected, and the quality of the basic and advanced life support interventions provided ${ }^{17-20}$. Neuroprotective treatments are very important after both in-hospital and out-of-hospital CPA. Accepted brain protective treatments include optimizing circulation, hypothermia, sedation, and avoiding hyperventilation/hyperglycemia/ hyperthermia ${ }^{16}$. Cardiac arrest occurred in our patient in the hospital. She received supportive treatment from the intensive care unit and there was no neurological sequelae in the patient after cardiac arrest.

In conclusion, in recent years IV paracetamol is frequently used in hospitalized patients to reduce fever and pain. Even though hypotension related to IV paracetamol is a rare complication, it needs to be watched closely because it can be life threatening.

\section{REFERENCES}

1. Chiam E, Weinberg L, Bellomo R. Paracetamol: a review with specific focus on the haemodynamic effects of intravenous administration. Heart Lung Vessel 2015;7:121-132.

2. Schmitt E. Paracetamol for injection: new formula. New formulation: why so widely used? Prescrire Int 2003; 12: 178.

3. Duggan ST, Scott LJ. Intravenous paracetamol (acetaminophen). Drugs2009; 69:101-113.
4. Niemi TT, Backman JT, Syrjala MT, Viinikka LU, Rosenberg PH. Platelet dysfunction after intravenous ketorolac or propacetamol. Acta Anaesthesiol Scand 2000; 44: 69-74.

5. de Maat MM, Tijssen TA, Bruggemann RJ, Ponssen $\mathrm{HH}$. Paracetamol for intravenous use in medium--and intensive care patients: pharmacokinetics and tolerance. Eur J Clin Pharmacol 2010; 66: 713-719.

6. Boyle M, Nicholson L, O’Brien M, et al. Paracetamol induced skin blood flow and blood pressure changes in febrile intensive care patients: An observational study. Aust Crit Care 2010; 23: 208-214.

7. Needleman SM. Safety of rapid intravenous of infusion acetaminophen. Proc (Bayl Univ Med Cent) 2013; 26: 235-238.

8. Bragadottir G, Redfors B, Ricksten SE. Mannitol increasesrenal blood flow and maintains filtration fraction and oxygenationin postoperative acute kidney injury: a prospectiveinterventional study. Crit Care 2012; 16: R159.

9. Wang JH, He Q, Liu YL, Hahn RG. Pulmonary edema inthe transurethral resection syndrome induced with mannitol5\%. Acta Anaesthesiol Scand 2009; 53: 10941096.

10. Duncan CN, Seet J, Baker S. Centrally administered parenteral paracetamol: A potentially under-reported cause of haemodynamic instability within the adult intensive careunit. Aust Crit Care 2012; 25: 131.

11. Picetti E, De Angelis A, Villani F, et al. Intravenous paracetamol for fever control in acute brain injury patients: cerebral and hemodynamic effects. Acta Neurochir (Wien) 2014; 156: 1953-1959.

12. Picetti E, Rossi I, Ceccarelli P, et al. Intravenous paracetamol for fever control in acute brain-injured patients: cerebral and hemodynamic effects. Crit Care 2013; 17: 1-200.

13. Vera P, Zapata L, Gich I, Mancebo J, Betbese AJ. Hemodynamic and antipyretic effects of paracetamol, metamizol and dexketoprofen in critical patients. Med Intensiva 2012; 36: 619-625.

14. Krajcova A, Matousek V, Duska F. Mechanism of paracetamol-induced hypotension in critically ill patients: a prospective observational cross-over study. Aust Crit Care 2013; 26: 136-141.

15. Heaps T, Gormley J.Cardiac arrest following paracetamol overdose complicated by hypokalaemia. Acute Med 2010; 9:127.

16. Kendirli T, Erkek N, Köroğlu T, et al. Cardiopulmonary Resuscitation in Children With In-Hospital and Outof-Hospital Cardiopulmonary Arrest: Multicenter Study From Turkey.Pediatr Emerg Care 2015;31:748-752.

17. Kleinman ME, Chameides L, Schexnayder SM, et al. Pediatric advanced life support: 2010 American Heart Association guidelines for cardiopulmonary resuscitation and emergency cardiovascular care. Circulation 2010;122(18 Suppl 3):876-908.

18. Olotu A, Ndritu M, Ismael M, et al. Characteristics and outcome of cardiopulmonary resuscitation in hospitalised African children. Resuscitation 2009;80:6972. 
19. Kitamura T, Iwami T, Kawamura T, et al. Conventional and chest-compression-only cardiopulmonary resuscitation by bystanders for children who have outof-hospital cardiac arrests: a prospective nationwide, population-based cohort study. Lancet 2010;375:13471354.
20. Raymond TT, Cunnynham CB, Thompson MT, et al. Outcomes among neonates, infants, and children after extracorporeal cardiopulmonary resuscitation for refractory in-hospital pediatric cardiac arrest: a report from the National Registry of Cardiopulmonary Resuscitation. Pediatr Crit Care Med 2010;11:362-371. 